\title{
Industry Level Supplier-Driven IT Spillovers
}

\author{
Zhuo (June) Cheng \\ Faculty of Business, Hong Kong Polytechnic University, Hung Hom, Kowloon, Hong Kong, afzcheng@inet.polyu.edu.hk \\ Barrie R. Nault \\ Haskayne School of Business, University of Calgary, Calgary, Alberta T2N 1N4, Canada, nault@ucalgary.ca
}

\begin{abstract}
$\mathrm{W}^{\mathrm{e}}$ e model and estimate the effects to downstream productivity from information technology (IT) investments made upstream. Specifically, we examine how an industry's productivity is affected by the IT capital stock of its suppliers. These supplier-driven IT spillovers occur because, due to competition in the supplying industry, quality benefits from suppliers' IT investments can pass downstream. If the output deflators of supplying industries (consequently the intermediate input deflator of the using industries) do not capture the quality improvement from IT, then the output productivity of the supplying industries is mismeasured or misassigned. We develop and empirically test a model capturing these supplier-driven effects using data on 85 manufacturing industries at the three-digit SIC code level. We find that for a $10.5 \%$ increase in suppliers' IT capital, the suppliers' output increases by $0.63 \%-0.70 \%$, which is more than covering the cost of the increase in suppliers' IT capital. In addition, this increase in suppliers' IT capital increases the average downstream industry's output by $\$ 66-\$ 72$ million, thereby confirming substantial supplier-driven IT spillovers downstream. We also infer the magnitude of the measurement error of the price deflator of the intermediate input resulting from the failure to account for IT-related quality improvement, finding that the measured price deflator overestimates the true deflator by approximately $30 \%$ at the mean level of IT capital.
\end{abstract}

Key words: value of IT; IT investment; IT quality; interorganizational systems (IOSs); production function framework; input-output tables; price deflator; IT contribution

History: Accepted by Wallace J. Hopp, information systems; received May 16, 2005. This paper was with the authors 10 months for 2 revisions. Published online in Articles in Advance July 20, 2007.

\section{Introduction}

In this paper, we model and estimate the effects to downstream productivity from information technology (IT) investments made upstream. Specifically, we examine how an industry's productivity is affected by the IT capital stock of its upstream suppliers. We adopt the production-function framework and add a spatial component to reflect industries' relative position in the industry value chain to capture the interindustry effects.

There are several reasons why we would expect an impact of suppliers' IT investment on a specific industry's productivity. First, suppliers' IT investment may translate into new or improved products, better customer service, and speed (Brynjolfsson and Hitt 2000), which are converted into features of intermediate inputs to the downstream industries. As the supplier industry becomes increasingly competitive, some of these benefits from IT investment cannot be captured, and are dissipated to downstream industries. That is, supplier competition causes benefits from IT investments to move downward along the value chain in the form of new or improved products and enhancements in intangible aspects of existing products like convenience, timeliness, quality, and variety. For example, raw material producers' deployment of radio frequency identification (RFID) tags helps the manufacturers reduce the unloading time, improve the accuracy of the inventory data, and cut down warehouse labor and inventory cost.

Second, industries rely on interorganizational systems (IOSs) to share information about demand and supply (Lee et al. 2000). Information sharing through such systems helps upstream suppliers to more accurately forecast demand, and as a result downstream customers also benefit from automated, accurate, and speedy order replenishment. In a research-in-progress study, Melville and Ramirez (2003) propose a conceptual framework to explore the processes of interfirm IT-value generation. IOSs enable a wide range of business processes and generate value for the business partners. Typically, such IOSs require IT investment by both partners and their IT investments are complementary in the sense that returns to IT investment are made more valuable by IT investment in neighboring industries. Therefore, suppliers' IT investment or joint IT investment in IOSs improves the quality-tangible or intangible - of the intermediate input for the downstream customers. Again, unless the suppliers have monopoly power, part or all of the benefit from the IOS-based quality improvement is passed on to the downstream customers, giving rise to supplier-driven 
IT spillovers. For example, Boeing Airplane Co.'s extranet allows commercial customers to place and track part orders on the Web and supplies information regarding 410,000 parts in stocks to 700 customers worldwide, which results in substantial increase in efficiency for Boeing's customers (Romano et al. 2001).

Despite the apparent benefit of IT investment by suppliers, there has been little research that has empirically studied the effects of IT investment between industries. We suspect that the principal difficulty in studying these effects has been the lack of data to specify and quantify the transaction relationship among value-chain partners. Because the primary impacts of an industry's IT investment follows its purchasing and selling transactions with other industries, without data on the transaction relationship between industries it is not possible to trace the impact of a given industry's IT investments on other industries. We resolve this lack of data by employing the economywide input-output tables (Chentrens and Andreassean 2001) produced by the U.S. Bureau of Labor Statistics (BLS). The use table (Chentrens and Andreassean 2001) shows the inputs to industry production and the commodities that are consumed by final users. Thus, the use table provides the value of output produced in one industry that is used by another industry for each pair of industries in the economy. As such, it provides measures of transaction volumes between industries that are value-chain partners: Measures that we convert into weights to capture the supplier-driven IT spillovers.

In a production economy, all the effects of IT capital investment upstream that impact downstream industries come through either changes in price or changes in quality of intermediate inputs. We develop a model for supplier-driven IT spillovers that explicitly accounts for the measurement error of the price deflator of the intermediate input, reflecting the mismeasurement of the quality enhancement provided by upstream IT investment. We use this mismeasurement along with a weighted aggregate of the suppliers' IT capital to develop an estimation form that gives us a measure of supplier-driven IT spillovers.

Using our estimation form, we then empirically estimate our model of supplier-driven IT spillovers using the multifactor productivity data set and the input-output tables obtained from the BLS. We find the supplier-driven IT spillovers to be both positive and significant. Not only is the increase in IT capital more than covered by the output increases in the industries where the IT investments are made, these increases in IT capital translate into increases in downstream output of $\$ 66-\$ 72$ million per downstream industry. In addition, we find that because of the failure to account for the quality improvement, the measured price deflator overestimates the true deflator by approximately $30 \%$ at the mean level of IT capital stock.

We organize this paper as follows. In the next section, we review the literature on IT value contribution and describe the sources of supplier-driven IT spillovers. In §3, we develop the model we use to estimate these supplier-driven spillovers. In $\S 4$ we empirically estimate our model using data on the three-digit manufacturing industries in the subsequent section. The last section discusses our contributions and concludes the paper.

\section{IT Value Contribution and IT Spillovers}

\subsection{Contribution of IT Investment Under Production-Function Framework}

The starting point of our modeling approach draws upon the information systems literature on the contribution of IT investment under the production-function framework. A production function relates output to the amount of the inputs, typically capital and labor. A commonly used functional form is the Cobb-Douglas production function (Cobb and Douglas 1928). During the late 1990s there was considerable research evaluating the contribution of IT investments, treating IT capital or IT labor, or both, as a separate input factor. This line of research has focused on the business unit level (Loveman 1994), firm level (Brynjolfsson and Hitt 1996), sector level (Oliner and Sichel 2000), and the country level (Dewan and Kraemer 2000).

Using data on 60 manufacturing small business units belonging to Fortune 500 companies, Loveman (1994) found that investments in IT showed no net contribution to total output. Lee and Barua (1999) argued that this negative result was due to the use of an incorrect IT deflator-Loveman used an index of computer prices to deflate IT capital-but because IT capital consists of more than just computers Loveman overdeflated the IT capital stock. Instead, Lee and Barua (1999) chose the U.S. Bureau of Economic Analysis (BEA) price index corresponding to the category "information processing and related equipment," which includes computers, communication equipment, instruments, and photocopiers and related equipment. They also argued the necessity of incorporating behavioral assumptions, such as profit maximizing or cost minimizing, and management inefficiencies in the estimation. Using the same data set as Loveman (1994), they showed significant positive returns from IT investment.

At the firm level, Brynjolfsson and Hitt (1996) used a data set consisting of 367 large firms to estimate the 
contribution of IT capital and labor. They found the gross marginal product (MP) for IT capital to be $81 \%$ for the average firm in their sample, meaning that each marginal dollar of IT capital added 0.81 dollar of output. In order to estimate the net benefit of IT capital stock, one needs an annual cost of IT capital; i.e., how much of the capital stock is "used up" each year and must be replaced to return to the level of the beginning of the year. Taking a conservative assumption of three-year service life gave an IT capital cost of $33 \%$ each year, which yielded a net MP estimate of $48 \%$. They also found a substantial net MP for IT labor. Lichtenberg (1995) focused on testing whether the IT investment yielded returns greater than those earned by other factors. He estimated these excess returns to be significant and positive. Both Brynjolfsson and Hitt (1996) and Lichtenberg (1995) used the Cobb-Douglas functional form, which constrains the elasticities of substitution for all pairs of inputs to unity. Dewan and Min (1997) argued that firms can substitute IT for labor or non-IT capital to take advantage of the price and performance improvements in IT. In order to study the substitution of IT for other input factors, they adopted a different functional form, the CES-translog, to estimate substitution elasticities. Their main result was that IT capital is a net substitute for both non-IT capital and labor, and that the Cobb-Douglas form was reasonable. Brynjolfsson and Hitt (2003) found a large long-run contribution of computers; and their explanation is that computer investment is complemented by time-consuming organization changes.

At the sector level, several studies examined the effect of IT spending on the growth rate of average labor productivity (ALP) and multifactor productivity (MFP), or the Solow residual, using the growthaccounting approach. ALP is defined as output perunit labor hour, and MFP growth is defined as the difference between output growth and the growth of a composite input, where the growth of the composite input is the weighted average of the growth of individual inputs with weights being their respective input shares in the value of output. This growthaccounting approach, developed by Solow (1957), uses a production-function framework assuming constant returns to scale and that factors are paid their marginal products. Using this approach, Oliner and Sichel (2000) found that IT accounted for about twothirds of the step-up in ALP growth between the first and second halves of 1990s, and that this conclusion largely held for the producers and users of IT. However, Gordon (2000) argued that the productivity revival based on IT capital primarily occurred within the $12 \%$ of the economy that produces computers and durable goods, whereas the remaining $88 \%$ of the economy did not experience any productivity growth from IT. He decomposed the productiv- ity growth into cyclical and trend effects, and argued that more than $20 \%$ of the productivity growth was transitory rather than permanent. In contrast, Baily and Lawrence (2001) showed that there had been a substantial structural acceleration of MFP outside of the computer sector, especially in the service industries that purchased IT. However, Stiroh (2002) also found that the IT-producing and IT-using industries accounted for all of the productivity revival, whereas the industries relatively isolated from the IT revolution contributed negatively to the productivity revival.

Using country-level data, Dewan and Kraemer (2000) estimated a Cobb-Douglas production function relating IT and non-IT inputs to gross domestic product output. They found a positive output elasticity for IT capital in developed countries and a negative output elasticity for IT capital, as well as a higher elasticity of non-IT capital, in developing countries. They attributed these differences to complementary investments in such factors as infrastructure and human capital, whereby IT can leverage these complementary investments for higher payoffs in developed countries. In a recent study, Mittal and Nault (2006) argued that, in addition to direct effects such as traditional substitution and complementarity of factor inputs, the contribution of IT capital occurs indirectly through technological progress where these indirect effects of IT capital arise through efficiency enhancements in the use of non-IT capital and labor. Developing a model incorporating these indirect efficiency-enhancing effects, and using almost 50 years of manufacturing industry data at the two-digit SIC code level from the United States, they found that indirect effects were significant in IT-intensive industries and that direct effects were significant in non-ITintensive industries, suggesting that industries which were more IT intensive were structurally different in their productive uses of IT.

In sum, using finer data and more advanced econometric techniques, the line of research on evaluating the contribution of IT investments under the production-function framework has converged on a positive IT contribution. That research has largely focused on the impact of own IT investment. Tallon et al. (2000, p. 146) suggest that "as the primary focus of these studies has been on the productivity impacts of IT, other impacts such as improved inventory management, greater product variety, and enhanced customer service have been excluded from an analysis of IT payoffs." We argue that suppliers' IT investment also has an impact on the downstream industry's productivity. In this study, we examine the impact of improved inventory management, greater product variety, and enhanced customer service enabled by suppliers' IT investment on downstream productivity. 


\subsection{Supplier-Driven IT Spillovers}

Suppliers' IT investments increase output quality in the form of new or improved products, or in enhancements in intangible aspects of existing products like convenience, timeliness, quality, and variety (Brynjolfsson and Hitt 2000). New products embed intelligence in the form of IT. IT investments in process monitoring and quality control significantly reduce defects in output. Computerized numerically controlled machines, which are computer-controlled machine tools designed to repeatedly manufacture complex parts in metals and other materials, increase precision. Flexible manufacturing technologies increase the variety of output and tailor output to the customer's specific needs. IOSs such as electronic data interchange (EDI) and business-to-business electronic commerce enable information sharing, which helps to reduce order cycle time, data-entry errors (Riggins and Mukhopadhyay 1994), lead times, inventory levels, and stockouts (Lee et al. 2000, Cachon and Fisher 2000). Vendor-managed inventory (VMI) systems shift the replenishment decision to upstream suppliers, significantly reducing inventory management costs for downstream customers (Çetinkaya and Lee 2000). For example, Mukhopadhyay et al. (1995) estimated the savings from Chrysler's use of EDI with its suppliers and their improved information exchanges to be $\$ 60$ per vehicle.

Brynjolfsson (1994) conducted a survey of managers to find out the relative importance of reasons for investing in IT. His results indicated that the primary reason for IT investment was customer service followed by cost savings, timeliness and quality. Unless the supplier has monopoly power, it cannot reap the full benefit from the improvement in output quality and customer service that result from investments in IT. Instead, as the supplier industry becomes more competitive, part or all of the benefits of investments in IT is dissipated to the downstream customers, giving rise to supplier-driven IT spillovers.

If the output deflators of supplying industries (consequently the intermediate input deflators of the using industries) do not capture the IT-based quality improvement in the intermediate inputs, then the output productivity of the supplying industries is mismeasured or at least misassigned. That is, if quality improvements in intermediate inputs are not incorporated in the deflator, then the deflated value of the intermediate inputs are understated. The BLS, which constructs the official price indices, generally does not adjust the index for the quality improvements embedded in the products (Griliches and Lichtenberg 1984). Baily and Lawrence (2001, p. 309) expressed similar concerns: "The deflators available for intermediate goods and services are often inadequate, so that productivity in one industry can be overstated at the expense of another."
This productivity mismeasurement or misassignment problem can be illustrated by the following example. Suppose industry 1 supplies personal computers to industry 2. Because of its IT investment, industry 1 is able to make faster personal computers. However, due to the competition in that industry, the faster personal computer can only be sold at the original price of the old computer. If the statistical agencies do not interpret this as a fall in the real price of a personal computer, then the measured productivity of industry 1 would show no increase. If industry 2 is able to produce more output using the faster personal computers than they could using the old computers, then an increase in productivity of industry 2 will be recorded. In this example, productivity of industry 1 is understated, and productivity of industry 2 is overstated.

The BLS has made some effort in quality adjustment using Hedonic methods (Griliches 1971) in some categories of products-for example, electronic computers (Sinclair and Catron 1990), apparel commodities (Liegey 1994), and consumer audio products (Kokoski et al. 2007). The Hedonic approach relies on the idea that any good can be interpreted as a bundle of characteristics. Even though the Hedonic approach offers promise for the quality adjustment in the price indices, it requires a large sample of data with detailed information on product characteristics that can be quantified or categorized for statistical analysis (Kokoski 1993). It is unlikely that BLS will make the quality adjustment for all product categories in the near future.

Our supplier-driven IT spillovers resemble R\&D spillovers. Griliches (1979) provided some interesting numerical examples of mismeasurement or misassignment of productivity growth resulting from the failure of the price index to account for the quality improvement enabled by the R\&D investments of upstream industries. Scherer (1982) distinguished between product- and process-oriented R\&D performed within an industry whereby process-oriented R\&D should contribute directly to the productivity growth in that industry. On the contrary, for product-oriented R\&D, under imperfectly monopolistic pricing, much of the benefit from superior new products is passed on to the customers. He found that the "imported" R\&D is an important determinant of productivity growth, contributing perhaps even more than some of the R\&D performed within an industry. Griliches and Lichtenberg (1984) reexamined the relationship and found similar results. We believe the effect of IT investment on value-chain neighbors exhibits a variant on this relationship: Customers benefit from improved or new products resulting from suppliers' IT investments. Our paper also 
Figure 1 The Supplier-Driven IT Spillovers

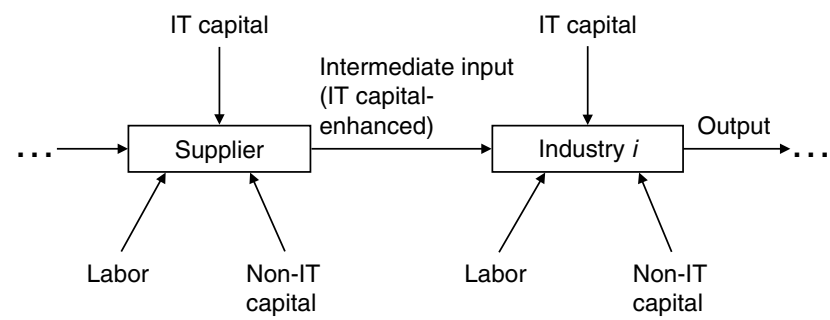

relates to the literature on macroeconomic complementarities, which documents the positive comovement of output across sectors over the business cycle (Conley and Dupor 2003, Cooper and Haltiwanger 1996, Bartelsman et al. 1994, Caballero and Lyons 1992). These studies used an extended production function adding the average level of output or inputs to capture the externalities, and the results generally confirmed the presence of complementarities across sectors.

A conceptual model of supplier-driven IT spillovers is shown in Figure 1. Industry $i$ uses non-IT capital, labor, and IT capital, and receives intermediate inputs from suppliers and produces output. Similarly, suppliers use non-IT capital, labor, and IT capital, along with intermediate goods further upstream to produce output-that is, intermediate inputs to industry $i$. Some of the benefits of the supplier's IT capital are embedded in the intermediate inputs in the form of new or improved products, or in enhancements in intangible aspects of existing products. As a consequence, industry $i$ benefits indirectly from the supplier's IT investment, and this is how supplier-driven IT spillovers occur.

\section{A Model of Supplier-Driven IT Spillovers}

Our model of supplier-driven IT spillovers is derived from the simple Cobb-Douglas production function,

$$
Y=A K^{\alpha} L^{\beta} Z^{\gamma} M^{\theta} \text {, }
$$

where $Y$ is the quantity of physical output; $K, L, Z$, and $M$ are the quantities of non-IT capital, labor, IT capital, and intermediate inputs, respectively. $A$ is the technological change parameter; and $\alpha, \beta, \gamma$, and $\theta$ are the output elasticities of non-IT capital, labor, IT capital, and intermediate inputs, respectively. Next we derive a model of supplier-driven IT spillovers by explicitly accounting for the errors in the measurement of intermediate input prices. The model is inspired by the one developed by Griliches and Lichtenberg (1984) to examine the effects of $R \& D$ investment. If we take the quantities of the inputs and of the output to be accurately measured, then using lowercase letters to represent the (natural) logs of the corresponding uppercase letters, the Cobb-Douglas production function for industry $i$ in $\log$ form is

$$
y_{i}=a+\alpha k_{i}+\beta l_{i}+\gamma z_{i}+\theta m_{i},
$$

where $m_{i}$ is the aggregate of all intermediate inputs for industry $i . m_{i}$ is given by

$$
m_{i}=\sum_{j \neq i} H_{j i} m_{j i}
$$

where $m_{j i}$ is the log of the $j$ th industry's intermediate input to industry $i$. To determine $m_{i}$ we use the alternative interpretation of the parameters from a Cobb-Douglas production function as factor shares. For industry $i, Y_{i}=A K_{i}^{\alpha} L_{i}^{\beta} Z_{i}^{\gamma} M_{i}^{\theta}$, where the quantity of intermediate input raised to its factor share can be written as the product of the intermediate inputs from individual industries raised to their factor shares: $M_{i}^{\theta}=\prod_{j \neq i} M_{j i}^{\theta_{j}}$, where $M_{j i}$ is the $j$ th industry's intermediate input to industry $i$ and $\theta_{j}$ is the factor share of intermediate input coming from industry $j$. Taking logs we have

$$
\theta m_{i}=\sum_{j \neq i} \theta_{j} m_{j i}=\theta \sum_{j \neq i} \frac{\theta_{j}}{\theta} m_{j i} .
$$

Then $\theta_{j} / \theta$ can be calculated as $H_{j i}$, which is the share of the $j$ th industry's intermediate input in the total value of intermediate inputs of industry $i$,

$$
H_{j i}=\frac{V_{j i}}{\sum_{j \neq i} V_{j i}},
$$

where $V_{j i}$ is the value of the $j$ th industry's intermediate input purchased by industry $i$. Variable $m_{i}$ is an aggregate of quantities used as inputs from the set of industries $j, j \neq i$.

We model the failure to adjust for changes in quality of the intermediate inputs-and hence the source of supplier-driven IT spillovers-as a measurement error in the price indices used to deflate the intermediate inputs,

$$
p_{j}=p_{j}^{*}+\epsilon_{j},
$$

where $p_{j}$ is the $\log$ of the measured deflator for $j$ th industry's intermediate input, $p_{j}^{*}$ is the log of the true deflator for $j$ th industry's intermediate input, and $\epsilon_{j}$ is the measurement error of the log of the $j$ th industry's intermediate input deflator. To get the measurement error of the actual deflator we take the exponential on both sides of (2) resulting in $P_{j}=P_{j}^{*} \cdot e^{\epsilon_{j}}$, where $e^{\epsilon_{j}}$ is the measurement error in the deflator of the $j$ th industry's intermediate input.

We expect the measurement error in the deflators to be positive, $\epsilon_{j}$. This reflects an overdeflation of the intermediate inputs-an overdeflation that occurs 
Figure 2 The Measurement Error in the Price Deflator

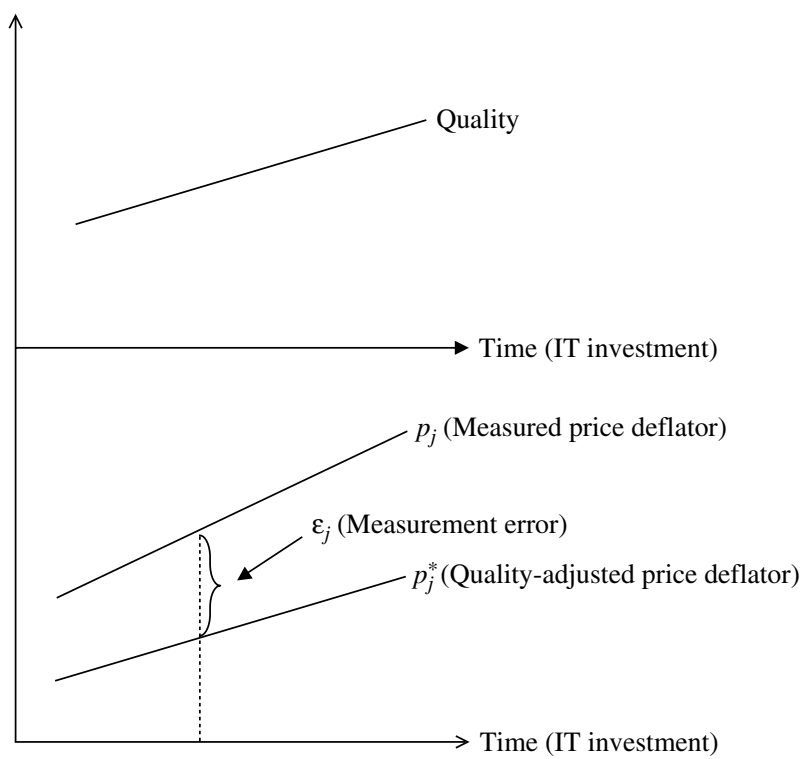

because the improvements in quality of the intermediate inputs due to upstream investments in IT are not fully reflected in the prices of the intermediate inputs. If these IT investment-related quality improvements were reflected in intermediate input prices, then the intermediate inputs would be priced lower-that is, the intermediate inputs would be deflated less and therefore the real value of the intermediate inputs would be higher. The top part of Figure 2 shows the quality of the intermediate inputs increasing over time. The lower part of Figure 2 shows the measured price deflator, which is not adjusted for quality, and the difference between this measured deflator and a quality-adjusted deflator. Deflators that do not adjust for quality improvements measure the deflator based on the full increase in price, whereas quality-adjusted deflators only measure the difference between the price increase and the quality increase. As the quality of intermediate inputs increases with upstream IT investment, the measurement error due to failure to account for the quality improvement becomes more severe with greater upstream IT investment.

Assuming that the current dollar value of intermediate purchases is measured without error, the quantity or constant dollar value of intermediate input is defined as the current dollar value of intermediate purchases divided by the price deflator. Deflating the value of the intermediate input with the measured deflator gives us the quantity of the $j$ th industry's intermediate input to industry $i$, which we denote as $M_{j i}$ :

$$
M_{j i}=V_{j i} / P_{j} .
$$

Because the measured deflator, $P_{j}$, is overstated due to the failure to account for quality improvement, the quantities of intermediate inputs are over-deflated and hence understated. Rewriting the above in log form we get

$$
m_{j i}=v_{j i}-p_{j} .
$$

If we deflate the value of the intermediate input using the true deflator that accounts for quality improvement, then in log form we have

$$
m_{j i}^{*}=v_{j i}-p_{j}^{*} .
$$

Combining these last two equations with (2) and eliminating the value of the intermediate input we can obtain the measurement error of the log of the $j$ th industry's intermediate input deflator in terms of the $\log$ of the intermediate input quantities

$$
m_{j i}^{*}-m_{j i}=p_{j}-p_{j}^{*}=\epsilon_{j}
$$

where the measured quantities of intermediate inputs are understated relative to the true (quality-adjusted) quantity: $m_{j i}^{*}>m_{j i}$.

In order to correctly estimate the coefficients in our Cobb-Douglas production function we should use the model with the true quantities of intermediate inputs, $m_{j i}^{*}$ :

$$
y_{i}=a+\alpha k_{i}+\beta l_{i}+\gamma z_{i}+\theta \sum_{j \neq i} H_{j i} m_{j i}^{*} .
$$

However, we do not observe the true intermediate input quantities $m_{j i}^{*}$. Instead, we only observe the measured (deflated) intermediate input quantities $m_{j i}$. Substituting $m_{j i}^{*}=m_{j i}+\epsilon_{j}$ from (3) into the above equation we get

$$
\begin{aligned}
y_{i} & =a+\alpha k_{i}+\beta l_{i}+\gamma z_{i}+\theta \sum_{j \neq i} H_{j i} m_{j i}+\theta \sum_{j \neq i} H_{j i} \epsilon_{j} \\
& =a+\alpha k_{i}+\beta l_{i}+\gamma z_{i}+\theta m_{i}+\theta \sum_{j \neq i} H_{j i} \epsilon_{j},
\end{aligned}
$$

where $m_{i}=\sum_{j \neq i} H_{j i} m_{j i}$ and because of the error in measurement we expect $\theta \sum_{j \neq i} H_{j i} \epsilon_{j}>0$.

As argued previously, the intermediate input deflator is mismeasured because it does not account for the quality improvement enabled by the suppliers' IT capital. Therefore, we assume that the extent of the mismeasurement of the $j$ th intermediate input deflator is proportional to the log of IT capital stock of supplying industry $j$,

$$
\epsilon_{j}=\mu \cdot z_{j},
$$

where the constant of proportionality is $\mu$. If $\mu=0$, then there is no error in measurement. This assumption that mismeasurement of the intermediate input deflator is proportional to the log of IT capital stock is the simplest form in which IT capital can 
have a spillover effect. ${ }^{1}$ With this proportional effect the weighted measurement error of the intermediate input deflator for industry $i$ is

$$
\sum_{j \neq i} H_{j i} \epsilon_{j}=\mu \sum_{j \neq i} \frac{V_{j i}}{\sum_{j \neq i} V_{j i}} z_{j} .
$$

In the last term in (6) $V_{j i} / \sum_{j \neq i} V_{j i}$ is the share of the $j$ th industry's intermediate input in the total value of intermediate inputs of industry $i$. Therefore, $\left(V_{j i} / \sum_{j \neq i} V_{j i}\right) z_{j}$ is an index of the benefits of industry $j$ 's IT capital enjoyed by industry $i$. Summing over the $j$ intermediate input industries aggregates the benefits of the suppliers' IT capital. We name this index, $\sum_{j \neq i}\left(V_{j i} / \sum_{j \neq i} V_{j i}\right) z_{j}$, as the supplier-driven IT index of industry $i$, and denote it as $s_{i}$.

Substituting (6) into (4), we get our Cobb-Douglas production function with the supplier-driven IT index

$$
y_{i}=a+\alpha k_{i}+\beta l_{i}+\gamma z_{i}+\theta m_{i}+\varphi \underbrace{\sum_{j \neq i} \frac{V_{j i}}{\sum_{j \neq i} V_{j i}} z_{j}}_{s_{i}},
$$

where the supplier-driven IT index is shown directly, and its coefficient is the product of the output elasticity of the intermediate inputs and the proportional (to IT capital) mismeasurement of the intermediate input deflator from (5), $\varphi=\theta \mu$. In capturing the extent of the mismeasurement in the intermediate input deflator, $\varphi$ captures the extent of supplier-driven IT spillovers. In (7) we account for the change in the quality of output due to an industry's own IT capital by including own IT capital.

In matrix notation we can define $\mathbf{W}_{s}$ as the weight matrix for supplier-driven IT spillovers with $V_{j i} / \sum_{j \neq i} V_{j i}$ as the $i j$ th element. $\mathbf{W}_{\mathbf{s}}$ is transformed from the input-output table whose $i j$ th element is the value of goods from industry $i$ used in industry $j$. Denoting $\mathbf{V}$ as the input-output table with $V_{i j}$ as the $i j$ th element and zeros as the diagonals, the matrix transformation is given by

$$
\mathbf{W}_{\mathrm{s}}=\operatorname{normw}\left(\mathbf{V}^{\prime}\right) \text {, }
$$

where $\mathbf{V}^{\prime}$ is the transpose of $\mathbf{V}$ and $\operatorname{normw}(\cdot)$ is a matrix operation used to normalize a matrix to get the rows to sum to unity. Thus, the $i j$ th element of $\operatorname{normw}\left(\mathbf{V}^{\prime}\right)$ is $V_{j i} / \sum_{j \neq i} V_{j i}$. Using this weight matrix (7) can be written as

$$
\mathbf{y}=\mathbf{X} \boldsymbol{\Phi}+\varphi \mathbf{W}_{\mathbf{s}} \mathbf{z}
$$

${ }^{1}$ If we find significant spillover effects through the intermediate input deflator by using this simple proportional form, then it is possible that more complex forms designed to fit the data may yield even stronger results.

\begin{tabular}{lrrrr} 
Table 1 & \multicolumn{4}{l}{$\begin{array}{l}\text { A Simple Input-Output Table of Four } \\
\text { Industries }\end{array}$} \\
\hline $\begin{array}{l}\text { Producing } \\
\text { industry }\end{array}$ & \multicolumn{4}{c}{ Using industry } \\
\cline { 2 - 5 } & 1 & 2 & 3 & 4 \\
\hline & 20 & 25 & 15 & 80 \\
2 & 0 & 25 & 0 & 120 \\
3 & 0 & 25 & 45 & 40 \\
4 & 20 & 0 & 0 & 60
\end{tabular}

where $\mathbf{y}$ is a $n \times 1$ matrix of observations on the output quantity, $\mathbf{X}$ is a $n \times 5$ matrix of observations, $\boldsymbol{\Phi}=$ $(a, \alpha, \beta, \gamma, \theta)^{\prime}$ is our vector of production parameters, $\mathbf{W}_{\mathrm{s}}$ is the weight matrix, and $\varphi$ is the supplier-driven IT spillover parameter.

\subsection{Measurement Error of Intermediate Input Price Deflators}

We can also infer the magnitude of measurement error of the intermediate input price deflators from the estimates of the parameters. As we showed in (2), we allow for a measurement error of $\epsilon_{j}$ in the $\log$ of the price deflator of the $j$ th intermediate input. In (5) we assume that $\epsilon_{j}$ is proportional (through $\mu$ ) to the $\log$ of IT capital stock of industry $j$. Combining these two equations and taking the exponential we get the relationship between the measured price deflator of the $j$ th intermediate input, $P_{j}$, and the true price deflator of the $j$ th intermediate input, $P_{j}^{*}$ :

$$
P_{j}=P_{j}^{*} \cdot Z_{j}^{\mu} .
$$

Then from (4), (6), and (7) we have $\mu=\varphi / \theta$, where $\mu$ is the proportional (to IT capital) mismeasurement of the intermediate input deflator from (5), $\varphi$ is the coefficient of the supplier-driven IT index, and $\theta$ is the output elasticity of the intermediate input.

\subsection{An Example}

Below we provide an example of a simple inputoutput table and show how the supplier-driven IT index is obtained using this input-output table as the weight matrix.

In Table 1 the $(1,2)$ element, 25 , is the value of goods purchased from industry 1 for use in production by industry 2 . The diagonal elements are transactions within industries, and because the diagonal elements do not reflect the interindustry effects, we set the diagonals to zero. As defined previously, $\mathbf{V}$ is the input-output table with diagonals set to zero:

$$
\mathbf{V}=\left(\begin{array}{cccc}
0 & 25 & 15 & 80 \\
0 & 0 & 0 & 120 \\
0 & 25 & 0 & 40 \\
20 & 0 & 0 & 0
\end{array}\right)
$$


The weight matrix for the supplier-driven IT effect, $\mathbf{W}_{\mathrm{s}}$, is obtained through

$$
\begin{aligned}
\mathbf{W}_{\mathbf{s}} & =\operatorname{normw}\left(\mathbf{V}^{\prime}\right) \\
& =\text { normw }\left(\begin{array}{cccc}
0 & 0 & 0 & 20 \\
25 & 0 & 25 & 0 \\
15 & 0 & 0 & 0 \\
80 & 120 & 40 & 0
\end{array}\right) \\
& =\left(\begin{array}{cccc}
0 & 0 & 0 & 1 \\
0.5 & 0 & 0.5 & 0 \\
1 & 0 & 0 & 0 \\
0.33 & 0.5 & 0.17 & 0
\end{array}\right) .
\end{aligned}
$$

From $\mathbf{W}_{\mathbf{s}}$ we can see that, for example, industry 2 has half of its intermediate inputs supplied by industry 1 and half by industry 3 , and industry 3 has all of its intermediate inputs supplied by industry 1 .

In order to calculate the supplier-driven IT indices, we need the vector of IT capital of the four industries, $\mathbf{Z}$. Take $\mathbf{Z}=(10,90,30,60)^{\prime}$ as an example, and therefore $\mathbf{z}=\log (\mathbf{Z})=(2.30,4.50,3.40,4.09)^{\prime}$. The supplier-driven IT indices can then be calculated as follows:

$$
\mathbf{s}=\mathbf{W}_{\mathrm{s}} \mathbf{z}=\left(\begin{array}{c}
4.09 \\
2.85 \\
2.30 \\
3.58
\end{array}\right) .
$$

Thus the supplier-driven IT index is an aggregation of the IT capital of the suppliers weighted by the fraction of the value of the goods purchased from each of the supplying industries one step upstream. Taking IT capital and the intermediate input weights from one level upstream means that our model does not include the propagation of IT capital multiple levels downstream.

\section{Empirical Estimation}

\subsection{Data Description}

Our data consists of two parts: the MFP data set for three-digit SIC code manufacturing industries from 1987 to 1999, and the input-output tables from 1983 to 1999. Both are obtained from the BLS. Matching the two data sets, we have complete data from 1987 to 1999 . The MFP data set contains 140 three-digit SIC code manufacturing industries and provides the series of output in millions of nominal (current) dollars and the output deflator. Dividing the output by the output deflator, we get the series for output in millions of 1987 dollars, $Y$. The MFP data set also provides us the series of intermediate purchase compensation in millions of nominal (current) dollars and the corresponding deflator, from which we get the series for intermediate inputs in millions of 1987 dollars, $M$. The MFP data set has labor input in millions of hours, $L$.

We requested data from BLS on IT capital stock. The data we received was a detailed breakdown of all assets for each three-digit SIC code manufacturing industry in 1987 dollars. There are 30 asset types, including computers and related equipment, office equipment, communication, instruments, photocopy and related equipment. We aggregated the productive stock of the five asset types listed above as the IT capital stock in millions of 1987 dollars, which we use as $Z$. We also requested the data on capital stocks in five categories of equipment, structure, inventories, land, and special tools that we also received in 1987 dollars. To get the non-IT capital stock, $K$, we total the equipment and structure components and subtract the IT capital stock from this number.

The input-output tables contain other industries besides those in manufacturing, and some of the rows/columns are the combination of more than one SIC code manufacturing industry. In order to match the two data sets, we eliminated all the nonmanufacturing industries from the input-output tables and we aggregated the MFP data set according to the input-output tables. After this data manipulation, we were left with 98 manufacturing industries. Because of missing MFP data for Logging, Newspapers, Periodicals, Books, and Miscellaneous Publishing in years 1997, 1998, and 1999, we exclude these categories for all years to obtain a balanced panel. ${ }^{2}$ We also exclude Ordnance and Ammunitions, Aerospace, Ship and Boat Building and Repairing, Railroad Equipment, Toys and Sporting Goods, Tobacco Products, and Footwear Except Rubber and Plastic because they do not supply intermediate inputs to other manufacturing industries. We drop Greeting Cards because it has both missing data and does not supply other manufacturing industries. Therefore the data we analyze is a balanced panel of 85 industries across 13 years.

Table 2 lists the 85 manufacturing industries, the SIC codes, and the industry numbers used in the inputoutput tables. Also listed is the proportion of manufacturing interindustry purchasing, which is defined as the ratio of interindustry purchasing from other manufacturing industries to interindustry purchasing from all other nongovernment industries (manufacturing and nonmanufacturing). Of the 85 industries, 64 industries $(75.3 \%)$ purchase more than half of their intermediate inputs from other manufacturing industries in at least one of our sample years. Therefore, we are confident that our analysis of the 85 manu-

\footnotetext{
${ }^{2}$ We analyzed the unbalanced panel with these industries included for years 1987-1996 and the results are similar to what we report here. Greeting Cards is excluded because it does not supply other manufacturing industries.
} 
Table 2

Three-Digit SIC Manufacturing Industry Description

\section{Industry}

numbers

Three-Digit SIC Manufacturing Industry Description

\begin{tabular}{|c|c|c|c|}
\hline numbers & SIC code (1987) & Industry title & interindustry purchasing, $\%$ \\
\hline 13 & 242 & Sawmills and planing mills & $51.4-66.5$ \\
\hline 14 & 243 & Millwork, plywood, and structural members & $60.8-64.3$ \\
\hline 15 & 244,249 & Wood containers and misc. wood products & $63.5-66.2$ \\
\hline 16 & 245 & Wood buildings and mobile homes & $74.9-79.1$ \\
\hline 17 & 251 & Household furniture & $68.1-69.7$ \\
\hline 18 & 254 & Partitions and fixtures & $64.1-65.8$ \\
\hline 19 & $252,253,259$ & Office and misc. furniture and fixtures & $63.2-65.3$ \\
\hline 20 & $321-323$ & Glass and glass products & $43.2-44.5$ \\
\hline 21 & 324 & Hydraulic cement & $23.7-26.9$ \\
\hline 22 & $325,326,328,329$ & Stone, clay, and misc. mineral products & $35.0-36.9$ \\
\hline 23 & 327 & Concrete, gypsum, and plaster products & $38.5-41.1$ \\
\hline 24 & 331 & Blast furnaces and basic steel products & $27.0-28.9$ \\
\hline 25 & 332 & Iron and steel foundries & $41.9-44.0$ \\
\hline 26 & 333 & Primary nonferrous smelting and refining & $10.3-11.7$ \\
\hline 27 & 334,339 & All other primary metals & $30.3-31.8$ \\
\hline 28 & 335 & Nonferrous rolling and drawing & $62.0-64.8$ \\
\hline 29 & 336 & Nonferrous foundries & $66.5-68.9$ \\
\hline 30 & 341 & Metal cans and shipping containers & $77.4-79.5$ \\
\hline 31 & 342 & Cutlery, handtools, and hardware & $66.0-68.0$ \\
\hline 32 & 343 & Plumbing and nonelectric heating equipment & $66.6-68.6$ \\
\hline 33 & 344 & Fabricated structural metal products & $67.5-70.5$ \\
\hline 34 & 345 & Screw machine products, bolts, rivets, etc. & $60.1-63.3$ \\
\hline 35 & 346 & Metal forgings and stampings & $64.8-67.8$ \\
\hline 36 & 347 & Metal coating, engraving, and allied services & $59.5-62.1$ \\
\hline 38 & 349 & Miscellaneous fabricated metal products & $63.1-64.9$ \\
\hline 39 & 351 & Engines and turbines & $72.0-74.2$ \\
\hline 40 & 352 & Farm and garden machinery & $65.5-68.0$ \\
\hline 41 & 353 & Construction and related machinery & $69.0-71.0$ \\
\hline 42 & 354 & Metalworking machinery and equipment & $60.6-62.5$ \\
\hline 43 & 355 & Special industry machinery & $64.6-66.5$ \\
\hline 44 & 356 & General industrial machinery and equipment & $62.1-64.6$ \\
\hline 45 & 357 & Computer and office equipment & $44.9-68.8$ \\
\hline 46 & 358 & Refrigeration and service industry machinery & $68.2-70.6$ \\
\hline 47 & 359 & Industrial machinery nec. & $59.2-61.0$ \\
\hline 48 & 361 & Electric distribution equipment & $64.7-67.9$ \\
\hline 49 & 362 & Electrical industrial apparatus & $60.0-64.9$ \\
\hline 50 & 363 & Household appliances & $72.6-74.7$ \\
\hline 51 & 364 & Electric lighting and wiring equipment & $61.6-63.6$ \\
\hline 52 & 365 & Household audio and video equipment & $74.5-88.4$ \\
\hline 53 & 366 & Communication equipment & $56.8-76.6$ \\
\hline 54 & 367 & Electronic components and accessories & $45.0-48.1$ \\
\hline 55 & 369 & Miscellaneous electrical equipment & $60.2-68.8$ \\
\hline 56 & 371 & Motor vehicles and equipment & $61.0-66.7$ \\
\hline 60 & 375,379 & Miscellaneous transportation equipment & $70.5-73.8$ \\
\hline 61 & 381 & Search and navigation equipment & $49.8-66.4$ \\
\hline 62 & 382 & Measuring and controlling devices & $58.3-69.5$ \\
\hline 63 & 384 & Medical equipment, instruments, and supplies & $55.7-62.8$ \\
\hline 64 & 385 & Ophthalmic goods & $42.0-43.9$ \\
\hline 65 & 386 & Photographic equipment and supplies & $51.6-56.4$ \\
\hline 66 & 387 & Watches, clocks, and parts & $42.0-54.3$ \\
\hline 67 & 391 & Jewelry, silverware, and plated ware & $58.3-62.2$ \\
\hline 69 & $393,395,396,399$ & Manufactured products nec. & $57.9-61.6$ \\
\hline 70 & 201 & Meat products & $5.1-5.5$ \\
\hline 71 & 202 & Dairy products & $16.3-17.7$ \\
\hline 72 & 203 & Preserved fruits and vegetables & $45.3-46.8$ \\
\hline 73 & 204,207 & Grain mill products, fats, and oils & $13.9-15.2$ \\
\hline 74 & 205 & Bakery products & $61.2-64.8$ \\
\hline 75 & 206 & Sugar and confectionery products & $23.5-24.9$ \\
\hline 76 & 208 & Beverages & $54.6-56.0$ \\
\hline 77 & 209 & Miscellaneous foods and kindred products & $29.7-31.2$ \\
\hline 79 & $221-224,226,228$ & Weaving, finishing, yarn and thread mills & $48.6-50.6$ \\
\hline 80 & 225 & Knitting mills & $75.2-78.0$ \\
\hline
\end{tabular}


Table 2

(Continued)

\begin{tabular}{lclc}
\hline $\begin{array}{l}\text { Industry } \\
\text { numbers }\end{array}$ & SIC code (1987) & \multicolumn{1}{c}{ Industry title } & $\begin{array}{c}\text { Proportion of manufacturing } \\
\text { interindustry purchasing, \% }\end{array}$ \\
\hline 81 & 227 & Carpets and rugs & $80.9-82.6$ \\
82 & 229 & Miscellaneous textile goods & $66.5-67.7$ \\
83 & $231-238$ & Apparel & $60.2-68.0$ \\
84 & 239 & Miscellaneous fabricated textile products & $73.0-78.4$ \\
85 & $261-263$ & Pulp, paper, and paperboard mills & $51.3-54.3$ \\
86 & 265 & Paperboard containers and boxes & $71.1-74.7$ \\
87 & 267 & Converted paper products except containers & $69.6-71.8$ \\
92 & 275,276 & Commercial printing and business forms & $65.2-69.2$ \\
94 & 278 & Blankbooks and bookbinding & $49.9-52.5$ \\
95 & 279 & Service industries for the printing trade & $37.2-48.4$ \\
96 & 281,286 & Industrial chemicals & $19.8-22.6$ \\
97 & 282 & Plastics materials and synthetics & $64.7-68.5$ \\
98 & 283 & Drugs & $24.0-26.1$ \\
99 & 284 & Soap, cleaners, and toilet goods & $52.1-53.8$ \\
100 & 285 & Paints and allied products & $69.7-73.1$ \\
101 & 287 & Agricultural chemicals & $32.3-35.9$ \\
102 & 289 & Miscellaneous chemical products & $57.7-61.3$ \\
103 & 291 & Petroleum refining & $2.2-2.6$ \\
104 & 295,299 & Miscellaneous petroleum and coal products & $62.3-67.9$ \\
105 & 301 & Tires and inner tubes & $56.7-62.3$ \\
106 & $302,305,306$ & Rubber products, plastic hose and footwear & $59.4-62.9$ \\
107 & 308 & Miscellaneous plastics products nec. & $63.1-66.4$ \\
109 & $311,315-317,319$ & Luggage, handbags, and leather products nec. & $68.4-72.7$
\end{tabular}

Notes. The industry number is the number used in the input-output tables. Proportion of manufacturing interindustry purchasing is defined as the ratio of the interindustry purchasing from other manufacturing industries to the interindustry purchasing from all other nongovernment industries (manufacturing and nonmanufacturing). The range given in the table is over the 13 years of our sample.

facturing industries captures a large proportion of the interindustry transaction in the economy. ${ }^{3}$

We set the diagonals in the input-output tables to zero in order to isolate the supplier-driven effectsrecall that the supplier-driven IT index is $s_{i}=$ $\sum_{j \neq i}\left(V_{j i} / \sum_{j \neq i} V_{j i}\right) z_{j}$, i.e., we exclude $j=i$ as we aggregate across $z_{j}$ using the input-output table as the weight matrix. The summary statistics of the 1,105 observations are provided in Table 3. Also included are the statistics of the supplier-driven IT index, which is, as defined earlier, a weighted aggregate of the logs of suppliers' IT capital stock. From this table, we can see that the mean output is $\$ 30,294.4 \mathrm{M}$ in 1987 dollars, and the mean IT capital is $\$ 1,814.49 \mathrm{M}$ in 1987 dollars-about $6 \%$ of the output level. The mean supplier-driven IT index is 7.21.

\subsection{Methodologies}

We estimate the simple Cobb-Douglas production function in (1) and the Cobb-Douglas production function with supplier-driven IT spillovers in (7).

Because our data set is a cross-sectional time series, we test for several potential econometric problems.

\footnotetext{
${ }^{3}$ We analyzed our data set excluding the six industries (industry number 26,70,71,73,96, and 103) that have low proportions of manufacturing interindustry purchasing (i.e., lower than $20 \%$ in at least one year), and found that the results are similar to what we report here.
}

The first is autocorrelation in the error terms. Anticipation of autocorrelation is reasonable in any industry because with relatively smooth business cycles one year's output is highly correlated with the prior year's output. If the responses to changes in business cycles do not occur with the same magnitude in each industry, then each industry may differ in its magnitude of autocorrelation. Using the Wooldridge test for autocorrelation in a panel data set (Wooldridge 2002), we find that first-order autocorrelation (AR1) is present in our data set for the simple Cobb-Douglas specification $(F$-statistic $=26.91)$ and for our model

Table 3 Summary Statistics

\begin{tabular}{lccccc}
\hline Variable & Obs. & Mean & Std. dev. & Min. & Max. \\
\hline $\begin{array}{l}\text { Output (in millions of } \\
\quad 1987 \text { dollars) }\end{array}$ & 1,105 & $30,294.4$ & $46,044.2$ & 557.62 & $738,130.8$ \\
$\begin{array}{c}\text { Non-IT capital stock } \\
\text { (in millions of }\end{array}$ & 1,105 & $20,641.51$ & $22,836.99$ & 461.8 & $135,540.6$ \\
$\quad$ 1987 dollars) \\
$\begin{array}{c}\text { Labor (in millions } \\
\text { of hours) }\end{array}$ & 1,105 & 414.45 & 342.97 & 12.2 & $2,350.9$ \\
$\begin{array}{c}\text { IT capital stock } \\
\text { (in millions of } \\
\quad 1987 \text { dollars) }\end{array}$ & 1,105 & $1,814.49$ & $3,165.67$ & 30.3 & $27,661.1$ \\
$\begin{array}{c}\text { Intermediate inputs } \\
\text { (in millions of } \\
\quad 1987 \text { dollars) }\end{array}$ & 1,105 & $16,970.93$ & $20,999.34$ & 313.18 & $202,082.5$ \\
$\begin{array}{c}\text { Supplier-driven } \\
\text { IT index (index) }\end{array}$ & 1,105 & 7.21 & 0.83 & 5.42 & \\
\hline
\end{tabular}


of supplier-driven IT spillovers $(F$-statistic $=27.23)$ at all reasonable levels of significance. The results of these tests imply that pooled ordinary least squares regressions are inappropriate for our analysis. Furthermore, the AR1 process is likely to be different across the industries, causing panel specific AR1 (PSAR1). We are able to use the likelihood ratio test to check whether the AR1 coefficients are common across the panels or panel specific because the regression with correction for AR1 is nested in the regression with correction for PSAR1. We find that in both the simple Cobb-Douglas specification $\left(\chi^{2}=758.74\right)$ and our supplier-driven model $\left(\chi^{2}=801.61\right)$ the null hypothesis of common AR1 coefficients is rejected at all reasonable levels of significance. Even though there can be problems with the likelihood ratio test when the error terms are autocorrelated, we have no prior reason to believe that the AR1 process should be common across panels. Therefore, we adjust for panel-specific AR1 processes instead of a common AR1 process in our estimations.

In addition to autocorrelation, the variances of the error terms are likely to be fluctuating over time (heteroskedasticity), and moreover the variances of the error terms are likely to be different across different industries causing panel-level heteroskedasticity. The reason for considering panel-level heteroskedasticity is that industries differ in size, make use of different vintages of production technology, and are affected differently by business cycles. We use the likelihood ratio test to check for the presence of this panel-level heteroskedasticity and find that for both the simple Cobb-Douglas specification $\left(\chi^{2}=1,765.09\right)$ and our supplier-driven IT spillovers model $\left(\chi^{2}=1,816.27\right)$, the null hypothesis of no panel-level heteroskedasticity is rejected at all reasonable levels of significance. Again there may be problems with the likelihood ratio test when the error terms are autocorrelated, but we have no prior reason to believe that heteroskedasticity should be common across panels.

Therefore, we have evidence that both panel specific autocorrelation and heteroskedasticity are potentially present in our data set. To adjust for these econometrically we estimate each of the simple CobbDouglas and our supplier-driven IT spillover model with the following error structure specification:

- Homoskedastic errors and AR1 process within industry with industry-specific AR1 coefficients (PSAR1).

- Heteroskedastic errors and AR1 process within industry with industry-specific AR1 coefficients ( $\mathrm{He}+$ PSAR1).

PSAR1 requires estimation of one parameter per industry (85) and He + PSAR1 requires estimation of two parameters per industry (170). We could not estimate our equations with econometric adjustments for heteroskedastic error structures with cross-sectional (industry) correlations because we do not have enough degrees of freedom in our data set. To estimate with adjustments for heteroskedastic crosssectionally correlated errors, we would need to estimate the lower triangle of the covariance matrix over the 85 industries. For the estimation we use generalized least squares (GLS) regressions; methods that allow us to make the econometric adjustments for the different assumed error structures. We use crosssectional time series GLS routines from the STATA (2005) statistical estimation software that allow us to specify the individual econometric adjustments for the errors.

\subsection{Regression Results}

We begin by estimating the parameters for the simple Cobb-Douglas production function in (1) for each of the different econometric adjustments for the errors. Estimating the simple Cobb-Douglas production function allows us to compare our results with those from the previous studies. Our results, and those from the previous studies, are shown in Table 4 . All of our estimates are significant at the 1\% level. Using our econometric adjustments of PSAR1 and He + PSAR1, respectively, our output elasticity estimates are for non-IT capital 0.052 and 0.059 , for labor 0.251 and 0.257 , and for intermediate inputs 0.666 and 0.653 . These estimates are consistent with those of previous findings when one recognizes that intermediate inputs were in part bundled with labor in Brynjolfsson and Hitt (1996), and that traditionally output elasticities of labor are 2-2.5 times that of total capital.

Our estimates of the output elasticity of IT capital, 0.077 and 0.076 , are also comparable to those of the previous literature on the value of IT. For example, Lichtenberg (1995) used two different data sources and estimated the output elasticity of IT capital to be 0.10 and 0.12. Brynjolfsson and Hitt (1996) estimated the output elasticity of IT capital to be 0.0169 . Dewan and Min (1997) found the output elasticity of IT to be 0.104 . Dewan and Kraemer (2000) estimated the output elasticity of IT at 0.051 for the developed countries. Mittal and Nault (2006) found the direct IT output elasticity to be 0.07 . Our estimates of the returns to scale are 1.046 and 1.045 for the PSAR1 adjustment and the He + PSAR1 adjustment, respectively, indicating slightly increasing returns to scale. The consistency of our estimates with those of the prior studies and the close-to-unity returns to scale provide face validity of our data set and econometric specifications in the context of previous research.

Next we turn to our main analysis: the estimation of our supplier-driven IT spillovers model. These regression results are reported in Table 5. The output elasticity estimates for non-IT capital, labor, IT capital, and 
Table 4 Comparison of Results of Our Simple Cobb-Douglas Production Function and Those from Previous Studies

\begin{tabular}{|c|c|c|c|c|c|c|c|}
\hline \multirow[b]{2}{*}{ No. } & \multirow[b]{2}{*}{ Description } & \multirow[b]{2}{*}{ Level of analysis } & \multicolumn{5}{|c|}{ Elasticity/coefficient estimates } \\
\hline & & & $\begin{array}{l}\text { Non-IT } \\
\text { capital }\end{array}$ & Labor & IT capital & $\begin{array}{l}\text { Intermediate } \\
\text { inputs }\end{array}$ & $\begin{array}{l}\text { Returns } \\
\text { to scale }\end{array}$ \\
\hline & Our simple Cobb-Douglas & Three-digit SIC industry & & & & & \\
\hline 1. & PSAR1 & - & $\begin{array}{l}0.052^{*} \\
(4.39)\end{array}$ & $\begin{array}{c}0.251^{*} \\
(22.21)\end{array}$ & $\begin{array}{c}0.077^{*} \\
(14.19)\end{array}$ & $\begin{array}{l}0.666^{*} \\
(59.35)\end{array}$ & 1.046 \\
\hline \multirow[t]{2}{*}{2.} & $\mathrm{He}+\mathrm{PSAR} 1$ & - & $\begin{array}{l}0.059^{*} \\
(5.92)\end{array}$ & $\begin{array}{c}0.257^{*} \\
(29.02)\end{array}$ & $\begin{array}{r}0.076^{*} \\
(16.50)\end{array}$ & $\begin{array}{l}0.653^{*} \\
(64.86)\end{array}$ & 1.045 \\
\hline & Previous studies & & & & & & \\
\hline 3. & $\begin{array}{l}\text { Lichtenberg (1995) } \\
\text { Computerworld }\end{array}$ & Firm & 0.333 & 0.507 & 0.10 & - & 0.94 \\
\hline 4. & $\begin{array}{l}\text { Lichtenberg (1995) } \\
\text { Info-week }\end{array}$ & Firm & 0.390 & 0.489 & 0.122 & - & 0.85 \\
\hline 5. & Brynjolfsson and Hitt (1995) & Firm & 0.242 & 0.472 & 0.0522 & - & 0.76 \\
\hline 6. & Brynjolfsson and Hitt (1996) & Firm & 0.0608 & 0.883 & 0.0169 & - & 0.98 \\
\hline 7. & Dewan and Min (1997) & Firm & 0.281 & 0.601 & 0.104 & - & 0.99 \\
\hline 8. & $\begin{array}{l}\text { Dewan and Kraemer (2000) } \\
\text { Developed countries }\end{array}$ & Country & 0.176 & 0.955 & 0.051 & - & 1.18 \\
\hline 9. & Mittal and Nault (2006) & 2-digit SIC industry & 0.27 & 0.69 & 0.07 & - & 1.03 \\
\hline
\end{tabular}

Notes. The "previous studies" part is adapted from Mittal and Nault (2006). Our sample size is 1,105. $t$-stat is in parentheses. He: Heteroskedastic error structure. PSAR1: Panel-specific AR1 error structure.

${ }^{*}$ Coefficient is significant at $1 \%$ for our estimates.

intermediate inputs are similar to our results from the simple Cobb-Douglas estimation. Therefore, in the following analysis, we focus on the coefficients of the supplier-driven IT index.

\subsection{Estimation Results for Supplier-Driven IT Spillovers}

Recall that our model of supplier-driven IT spillovers is

$$
y_{i}=a+\alpha k_{i}+\beta l_{i}+\gamma z_{i}+\theta m_{i}+\varphi \sum_{j \neq i} \frac{V_{j i}}{\sum_{j \neq i} V_{j i}} z_{j},
$$

where suppliers' IT capital is captured in the last term. The regression results for this model are presented in Table 5. The estimates of the coefficient for the supplier-driven IT index, $\varphi$, are all positive and significant at the $1 \%$ level across different econometric specifications. The estimates of $\varphi$ are 0.024 and 0.022 for the PSAR1 adjustment and He + PSAR1 adjustments, respectively, indicating that there are significant and positive effects of upstream IT capital on downstream production.
To investigate the possibility of simultaneity bias caused by correlations between the IT capital inputs and the error term, and similarly the possibility that omitted variables such as other productivity-related organizational initiatives may result in such correlations, we tested for the exogeneity of our IT capital inputs. Our tests could not reject the hypothesis that our IT capital inputs are exogenous. In addition, labor and intermediate inputs can react more quickly to price changes whereas capital tends to be sticky. Our tests for the exogeneity of labor and intermediate inputs could not reject the hypotheses that these inputs are exogenous.

4.4.1. Interpretation of the Estimates of the IT Spillover Coefficient. As we see in the summary statistics table, Table 3, the mean of the supplierdriven IT index is 7.21. The coefficient of the supplierdriven IT index, $\varphi$, tells us that if the supplier-driven IT index of industry $i$ increases by 0.1 , then the output of industry $i$ would increase by $0.1 \times \varphi \times 100 \%$. In addition, the supplier-driven IT index would increase

Table 5 Regression Results for the Model of Supplier-Driven IT Spillovers

\begin{tabular}{|c|c|c|c|c|c|c|c|}
\hline \multirow[b]{2}{*}{ No. } & \multirow[b]{2}{*}{$\begin{array}{l}\text { Regressions } \\
\text { Supplier-driven }\end{array}$} & \multicolumn{6}{|c|}{ Elasticity/coefficient estimates } \\
\hline & & Non-IT capital & Labor & IT capital & $\begin{array}{l}\text { Intermediate } \\
\text { inputs }\end{array}$ & SUP & $\begin{array}{l}\text { Returns } \\
\text { to scale }\end{array}$ \\
\hline 1. & PSAR1 & $0.063^{*}(5.90)$ & $0.251^{*}(24.86)$ & $0.060 *(9.9$ & $0.661^{*}(58.84)$ & $0.024 *(4.14)$ & 1.035 \\
\hline 2. & $\mathrm{He}+\mathrm{PSAR} 1$ & $0.068^{*}(7.48)$ & $0.251 *(32.96)$ & $0.067^{*}(13.72)$ & $0.646 *(65.31)$ & $0.022 *(5.59)$ & 1.032 \\
\hline
\end{tabular}

Notes. Sample size is 1,105. $t$-stat is in parentheses. SUP: Supplier-driven IT index. He: Heteroskedastic error structure. PSAR1: Panel-specific AR1 error structure. ${ }^{*}$ Coefficient is significant at $1 \%$. 
by 0.1 if all the suppliers increase their IT capital by $10.5 \%\left(e^{0.1}=1.105\right)$. Recall that the expression for the supplier-driven IT index is $s_{i}=\sum_{j \neq i}\left(V_{j i} / \sum_{j \neq i} V_{j i}\right) z_{j}$. If all the suppliers increase their IT capital, $Z_{j}$, by $10.5 \%$, then the natural $\log$ of their IT capital, $z_{j}$, would increase by 0.1 , which would translate into an increase of 0.1 on the supplier-driven IT index. In other words, if all the suppliers of industry $i$ increase their IT capital by $10.5 \%$, then they would not only increase their own output by $0.105 \times \gamma \times 100 \%$ (where $\gamma$ is the output elasticity of own IT capital), but also the output of downstream industry $i$ by $0.1 \times \varphi \times 100 \%$.

As an example, consider the estimates from the regression with the PSAR1 adjustment. The coefficient estimate for the supplier-driven IT index is 0.024, and the output elasticity of IT capital is estimated to be 0.060 . If all the suppliers of industry $i$ increase their IT capital by $10.5 \%$, then the suppliers' output would increase by $0.63 \%$. The output of industry $i$ would also be affected by this increase due to supplier-driven IT spillovers and output would increase by $0.24 \%$. The estimates of $\varphi$ and $\gamma$ from the regression with the He + PSAR1 adjustment are 0.022 and 0.067 , respectively. Doing similar calculations as above with these estimates: If all the suppliers of industry $i$ increase their IT capital by $10.5 \%$, then their own output would increase by $0.70 \%$, and the output of industry $i$ would increase by $0.22 \%$.

Converting to annual dollar amounts: If all the suppliers of industry $i$ increase their IT capital by $10.5 \%$, then this would mean an increase in the IT capital stock of each supplier of $\$ 190.52 \mathrm{M}$ in 1987 dollars $(\$ 1,814.49 \mathrm{M} \times 10.5 \%)$ at the mean (pooled) IT capital stock level. The suppliers' own output would increase individually by between $\$ 190.85 \mathrm{M}$ $(\$ 30,294.4 \mathrm{M} \times 0.060 \times 10.5 \%$ for PSAR1 $)$ and $\$ 213.12 \mathrm{M}$ $(\$ 30,294.4 \mathrm{M} \times 0.067 \times 10.5 \%$ for He + PSAR1 $)$ in 1987 dollars at the mean (pooled) output level.

Furthermore, we find that because of the supplierdriven IT spillovers, with a $10.5 \%$ increase in upstream IT capital, the downstream industry-industry $i$-would have an increase in output of between $\$ 66.65 \mathrm{M}(\$ 30,294.4 \mathrm{M} \times 0.22 \%$ for He + PSAR1 $)$ and $\$ 72.71 \mathrm{M}(\$ 30,294.4 \mathrm{M} \times 0.24 \%$ for PSAR1 $)$ in $1987 \mathrm{dol}-$ lars at the mean (pooled) output level. Thus, this positive externality downstream of IT capital upstream is $\$ 66.65 \mathrm{M}-\$ 72.71 \mathrm{M}$ of downstream output in 1987 dollars.

To summarize, if all the suppliers of industry $i$ increase their IT capital by $10.5 \%$ or on average $\$ 190.52 \mathrm{M}$ in 1987 dollars, then the supplier-driven IT index would increase by 0.1. Depending on the econometric specifications, the output of the suppliers would increase by $0.63 \%-0.70 \%$, or $\$ 190.85 \mathrm{M}-$ $\$ 215.12 \mathrm{M}$ in 1987 dollars. In addition, because of the increase in their suppliers' IT, the output of industry $i$ would increase by $0.22 \%-0.24 \%$, or $\$ 66.65 \mathrm{M}-\$ 72.71 \mathrm{M}$ in 1987 dollars. $^{4}$

4.4.2. Inference on the Measurement Error of Intermediate Price Deflators. We can also infer the magnitude of measurement error of the intermediate price deflators from the estimates of the parameters. Earlier we derived the relationship between the measured price deflator of $j$ th intermediate input, $P_{j}$, and the true price deflator of $j$ th intermediate input, $P_{j}^{*}$ as

$$
P_{j}=P_{j}^{*} \cdot Z_{j}^{\mu},
$$

or in logs as

$$
p_{j}=p_{j}^{*}+\mu z_{j},
$$

where $\mu=\varphi / \theta$ and $\mu z_{j}=\epsilon_{j}$. Recall that $\varphi$ is the coefficient of the supplier-driven IT index, and $\theta$ is the output elasticity of intermediate inputs. If there is no error in the measurement of the intermediate inputs deflator, then $\mu=0$. The estimation with the PSAR1 adjustment gives us an estimate of 0.661 for $\theta$ and 0.024 for $\varphi$, from which we get an estimate of 0.0363 for $\mu$. This means that at the average (pooled) IT capital level, the measured price deflator of the intermediate input overestimates the true price deflator by $31.3 \%\left(1,814.49^{0.0363}=1.313\right)$ in any given year because of the failure to account for the quality improvement of the intermediate input. The estimates for $\theta$ and $\varphi$ from the regression with the He + PSAR1 adjustment are 0.646 and 0.022 , respectively. This means that at the average (pooled) IT capital level, the measurement error is $29.1 \%\left(1,814.49^{(0.022 / 0.646)}=1.291\right)$.

IT capital stock has steadily increased over the years. In the most recent year of our sample data, 1999 , the IT capital stock averaged $\$ 3,019.80 \mathrm{M}$ (in 1987 dollars) over the 85 three-digit SIC manufacturing industries. At this mean level of IT capital stock, the measurement error is estimated to be $33.8 \%$ $\left(3,019.80^{(0.024 / 0.661)}=1.338\right)$ for the regression with the PSAR1 adjustment, and $31.4 \%\left(3,019.80^{(0.022 / 0.646)}=\right.$ 1.314) for the regression with the He + PSAR1 adjustment.

In sum, we find the measurement error of the price deflator of the intermediate input to be $29.1 \%-31.3 \%$ at the mean (pooled) IT capital stock level, and 31.4\%$33.8 \%$ at the 1999 mean IT capital stock level. Because we modeled the mismeasurement of the intermediate input deflator as proportional to IT capital stock, the higher the suppliers' IT capital stock level such as what occurs over the period of our sample, the more severe the measurement error.

\footnotetext{
${ }^{4}$ We also considered the competitiveness of upstream supplier industries on our measure of IT spillovers. As we detail in the appendix, using the Herfindahl-Hirschman Index (HHI) as a measure of industry concentration and including this measure in our analysis, we find industry concentration does not significantly explain output. This could be because most manufacturing industries are relatively competitive.
} 


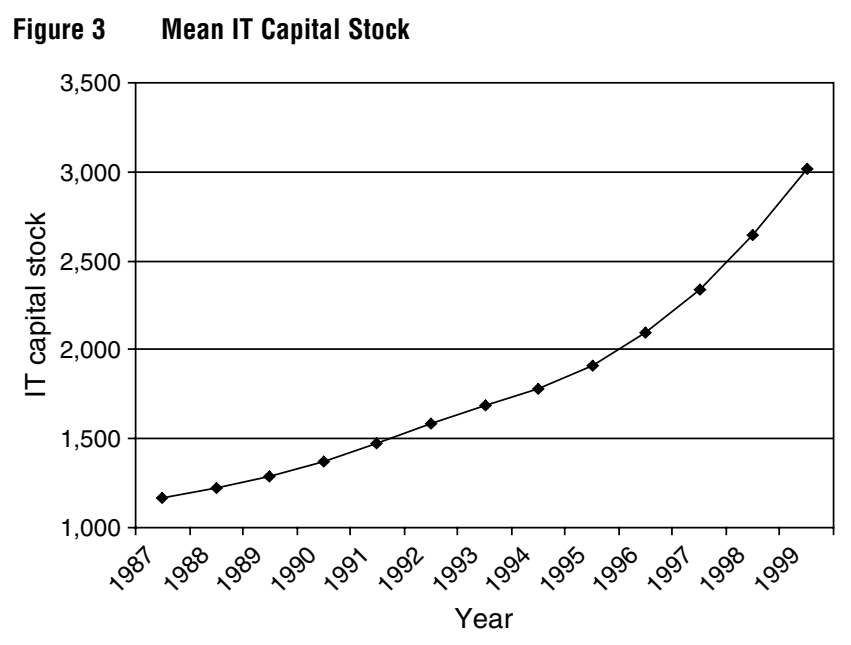

\subsection{Time Splits}

IT capital stock has steadily increased over the years. Figure 3 plots the mean IT capital stock level from 1987 to 1999 and it shows that the IT capital stock increased at a faster rate from 1993 to 1999 . We also plot the average IT intensity, defined as the ratio of IT capital stock to output, over the sample period (Figure 4). There is a mild inflection point at the year 1993. In order to see the effect of the changes in IT capital stock and IT intensity on the coefficient of the simple Cobb-Douglas and our supplier-driven model, we split the sample into two subperiods: 1987-1992 and 1993-1999, and run the regressions on the two subperiods. The results are reported in the first part of Table 6. In order to check whether the results are sensitive to where we make the split, we also ran the regression on the subperiods 1987-1993 and 19941999 , and these results are reported in the second half of Table 6. As we can see, the results from the two different time splits are similar. In all time splits the output elasticities and the coefficient of our supplierdriven IT index are significant at $1 \%$. Therefore, we discuss the time split of 1987-1992 and 1993-1999 in the following analysis.

4.5.1. Interpretation of the Estimates of the Coefficient of the Supplier-Driven IT Index by Time Period. Between the two periods we find minor reductions in $\varphi$, the coefficient of our supplier-driven IT index. We find that the output elasticities of both IT capital and of non-IT capital are higher in the latter period, and the output elasticity of intermediate inputs is correspondingly lower.

Converting our estimates into dollar implications, the mean IT capital stock for $1987-1992$ is $\$ 1,351.44 \mathrm{M}$ and the mean output is $\$ 24,941.32 \mathrm{M}$, both in 1987 dollars. If, as before, all the suppliers of industry $i$ increase their IT capital by $10.5 \%$, then this would result in an increase of IT capital of each supplier by $\$ 141.90 \mathrm{M}$
Figure $4 \quad$ Mean IT Intensity

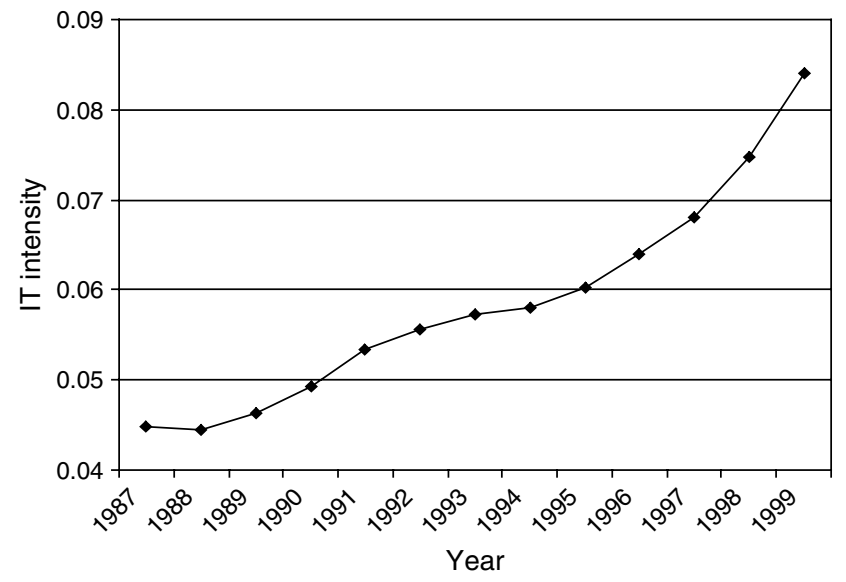

in 1987 dollars $(\$ 1,351.44 \mathrm{M} \times 10.5 \%)$ at the average 1987-1992 IT capital level. The suppliers' own output would increase individually by between $\$ 157.13 \mathrm{M}$ $(\$ 24,941.32 \mathrm{M} \times 0.060 \times 10.5 \%$ for PSAR1 $)$ and $\$ 164.99 \mathrm{M}$ $(\$ 24,941.32 \mathrm{M} \times 0.063 \times 10.5 \%$ for He + PSAR1 $)$ in 1987 dollars at the 1987-1992 output level. Because of the supplier-driven IT spillovers, the downstream industry, industry $i$, would have an increase in output of between $\$ 72.33 \mathrm{M}(\$ 24,941.32 \mathrm{M} \times 0.29 \%$ for PSAR1) and $\$ 87.29 \mathrm{M}(\$ 24,941.32 \mathrm{M} \times 0.35 \%$ for He + PSAR1) in 1987 dollars at the 1987-1992 output level.

For 1993-1999, the mean IT capital stock is $\$ 2,211.39 \mathrm{M}$ and the mean output is $\$ 34,882.74 \mathrm{M}$ in 1987 dollars. If all the suppliers of industry $i$ increase their IT capital by $10.5 \%$, then this would result in an increase in IT capital of each supplier of $\$ 232.20 \mathrm{M}$ $(\$ 2,211.39 \mathrm{M} \times 10.5 \%)$ in 1987 dollars at the 1993-1999 average IT capital level. The suppliers' own output would increase individually between $\$ 369.93 \mathrm{M}$ $(\$ 34,882.74 \mathrm{M} \times 0.101 \times 10.5 \%$ for PSAR1 $)$ and $\$ 373.59 \mathrm{M}$ $(\$ 34,882.74 \mathrm{M} \times 0.102 \times 10.5 \%$ for He + PSAR1 $)$ in 1987 dollars at the average 1993-1999 output level. As a result of the supplier-driven IT spillovers, the downstream industry, industry $i$, would have an increase of output between $\$ 90.70 \mathrm{M}(\$ 34,882.74 \mathrm{M} \times 0.26 \%$ for PSAR1) and $\$ 87.29 \mathrm{M}(\$ 34,882.74 \mathrm{M} \times 0.28 \%$ for HE + PSAR1) in 1987 dollars at the mean 1993-1999 output level.

In both subperiods, the additional output of the supplying industries resulting from a $10.5 \%$ increase in IT capital is not only higher than the increase in IT capital stock, but the upstream increase in IT capital stock confers a substantial increase in downstream output.

4.5.2. Inference on the Measurement Error of Intermediate Price Deflators by Time Period. For 1987-1992, the measurement error of the price defla- 
Table 6 Estimation Results of the Time Splits

\begin{tabular}{|c|c|c|c|c|c|c|c|c|}
\hline \multirow[b]{2}{*}{ Subperiods } & \multirow[b]{2}{*}{ No. } & \multirow[b]{2}{*}{ Regressions } & \multicolumn{6}{|c|}{ Elasticity/coefficient estimates } \\
\hline & & & $\begin{array}{l}\text { Non-IT } \\
\text { capital }\end{array}$ & Labor & IT capital & $\begin{array}{l}\text { Intermediate } \\
\text { inputs }\end{array}$ & SUP & $\begin{array}{l}\text { Returns } \\
\text { to scale }\end{array}$ \\
\hline \multicolumn{9}{|l|}{ Time split 1} \\
\hline 1987-1992 & & Simple Cobb-Douglas & & & & & & \\
\hline \multirow[t]{5}{*}{ Obs.: 510} & 1. & PSAR1 & $0.053^{*}$ & $0.234^{*}$ & $0.069^{*}$ & $0.670^{*}$ & - & 1.026 \\
\hline & 2. & $\mathrm{He}+\mathrm{PSAR} 1$ & $0.058^{*}$ & $0.243^{*}$ & $0.071^{*}$ & $0.657^{*}$ & - & 1.029 \\
\hline & & Supplier-driven & & & & & & \\
\hline & 3. & PSAR1 & $0.050^{*}$ & $0.250^{*}$ & $0.060^{*}$ & $0.669 *$ & $0.035^{*}$ & 1.029 \\
\hline & 4. & $\mathrm{He}+\mathrm{PSAR} 1$ & $0.057^{*}$ & $0.247^{*}$ & $0.063^{*}$ & $0.660^{*}$ & $0.029 *$ & 1.027 \\
\hline 1993-1999 & & Simple Cobb-Douglas & & & & & & \\
\hline \multirow[t]{5}{*}{ Obs.: 595} & 5. & PSAR1 & $0.088^{*}$ & $0.242^{*}$ & $0.101^{*}$ & $0.623^{*}$ & - & 1.054 \\
\hline & 6. & $\mathrm{He}+\mathrm{PSAR} 1$ & $0.094^{*}$ & $0.242^{*}$ & $0.100^{*}$ & $0.618^{*}$ & - & 1.054 \\
\hline & & Supplier-driven & & & & & & \\
\hline & 7. & PSAR1 & $0.092^{*}$ & $0.258^{*}$ & $0.101 *$ & $0.601^{*}$ & $0.026^{*}$ & 1.052 \\
\hline & 8. & $\mathrm{He}+\mathrm{PSAR} 1$ & $0.097^{*}$ & $0.257^{*}$ & $0.102^{*}$ & $0.590^{*}$ & $0.028^{*}$ & 1.046 \\
\hline \multicolumn{9}{|l|}{ Time split 2} \\
\hline 1987-1993 & & Simple Cobb-Douglas & & & & & & \\
\hline \multirow[t]{5}{*}{ Obs.: 595} & 1. & PSAR1 & $0.055^{*}$ & $0.234^{*}$ & $0.069 *$ & $0.667^{*}$ & - & 1.025 \\
\hline & 2. & $\mathrm{He}+\mathrm{PSAR} 1$ & $0.061^{*}$ & $0.241^{*}$ & $0.070^{*}$ & $0.656^{*}$ & - & 1.028 \\
\hline & & Supplier-driven & & & & & & \\
\hline & 3. & PSAR1 & $0.058^{*}$ & $0.250^{*}$ & $0.055^{*}$ & $0.662^{*}$ & $0.043^{*}$ & 1.025 \\
\hline & 4. & $\mathrm{He}+\mathrm{PSAR} 1$ & $0.066^{*}$ & $0.246^{*}$ & $0.055^{*}$ & $0.652^{*}$ & $0.038^{*}$ & 1.019 \\
\hline 1994-1999 & & Simple Cobb-Douglas & & & & & & \\
\hline \multirow[t]{5}{*}{ Obs.: 510} & 5. & PSAR1 & $0.124^{*}$ & $0.230^{*}$ & $0.108^{*}$ & $0.583^{*}$ & - & 1.045 \\
\hline & 6. & $\mathrm{He}+\mathrm{PSAR} 1$ & $0.123^{*}$ & $0.235^{*}$ & $0.109^{*}$ & $0.579^{*}$ & - & 1.046 \\
\hline & & Supplier-driven & & & & & & \\
\hline & 7. & PSAR1 & $0.124^{*}$ & $0.248^{*}$ & $0.103^{*}$ & $0.573^{*}$ & $0.028^{*}$ & 1.048 \\
\hline & 8. & $\mathrm{He}+\mathrm{PSAR} 1$ & $0.119^{*}$ & $0.257^{*}$ & $0.100 *$ & $0.570^{*}$ & $0.033^{*}$ & 1.046 \\
\hline
\end{tabular}

Notes. SUP: Supplier-driven IT index. He: Heteroskedastic error structure. PSAR1: Panel-specific AR1 error structure. ${ }^{*}$ Coefficient is significant at $1 \%$.

tor is estimated to be $45.8 \%\left(1,351.44^{(0.035 / 0.669)}=\right.$ 1.458) for PSAR1 and $37.3 \%\left(1,351.44^{(0.029 / 0.660)}=\right.$ 1.373) for He + PSAR1. For 1993-1999, the measurement error of the price deflator is estimated to be $39.5 \%\left(2,211.39^{(0.026 / 0.601)}=1.395\right)$ for PSAR1 and $44.1 \%$ $\left(2,211.39^{(0.028 / 0.590)}=1.441\right)$ for He + PSAR1. Thus, in both of the subperiods the measurement error is estimated to be slightly larger than that for the pooled sample.

\section{Conclusion}

In our analysis we examined how one industry's productivity is affected by the IT investment of its suppliers. Our argument for supplier-driven IT spillovers is that suppliers' IT investments translate into new or improved products, better customer service, and speed, which is in turn used as part of intermediate inputs employed by downstream industries. In addition, IOSs enable demand information sharing, which allows customers to benefit from automated, accurate, and rapid order replenishment. As the supplier industry becomes increasingly competitive, some of that industry's benefit from IT investment is dissipated to downstream industries. If the output deflators of supplying industries do not capture the quality improvement in intermediate inputs created by the IT and the IT-supported transactions around these inputs, then the output productivity of the supplying industries is mismeasured or at least misassigned.

Using an estimation model we developed for supplier-driven IT spillovers that explicitly considers the measurement of the price deflator of the intermediate inputs, we found that if all its suppliers increase their IT capital by $10.5 \%$, then the output of an industry increases by $0.22 \%-0.24 \%$, depending on the econometric specification. Translating these quantities into dollars, we found that such an increase in IT capital would yield similar or greater increases in output in the industry that makes the IT capital investment, and in addition these upstream IT capital investments would yield substantial output increases downstream. We also found that the measured price deflator overestimates the true deflator by $29.1 \%-31.3 \%$ at the mean IT capital stock level, because of this failure to account for intermediate input quality improvements.

Our study of supplier-driven IT spillovers has two important contributions, and is the first study to 
examine this type of IT spillover at the industry level. The first contribution is providing a mechanism through which the supplier-driven IT spillovers occur based on a mispricing of intermediate inputs using the well-established production-function framework. The second is showing that these effects are not only statistically significant but substantial in that IT investment resulting in increased IT capital stock upstream has large effects on downstream output. ${ }^{5}$

There are also policy and managerial implications of our findings. Our spillovers from upstream industry IT investment that are unaccounted for in the upstream industries suggest that upstream industries underinvest in IT relative to what would be optimal in a fully integrated economy. As the economy is a network of industries, this means that many industries are underinvesting in IT. Moreover, as our analysis only measures IT spillovers between trading partners, any returns further downstream accentuates the economywide underinvestment in IT. To increase social welfare, planners could employ policy instruments such as subsidies or tax relief to encourage IT investment, mitigating the underinvestment in IT. This has the potential to not only benefit industries but-should these benefits propagate through the value chain to final consumers-to enhance consumer welfare as well.

At the industry level initiatives could be taken by supply chain partners to internalize the positive externality from IT investment that upstream partners send downstream. Joint investments in IT, joint ventures with IT, joint ownership of IT capital, and even vertical integration are organizational methods to provide some of the returns from IT spillovers to those that make investment decisions. When planning and evaluating IT investments, managers should consider the benefits these investments may provide to downstream partners. Should some of the returns from these investments be recoverable through sharing agreements such as those suggested in Mahajan and Vakaria (2004), where a onetime transfer between value-chain members is proposed, then justifying and executing IT investments that incorporate the spillover may increase investments and profits for all value-chain partners. However, the bargaining for this type of agreements or other contractual solutions are complicated by situations of strategic necessity, whereby IT investments are made by upstream members simply to keep up with competitions.

There are several limitations of our analysis. First, there are many unobservable variables that could contribute to downstream IT spillovers, such as business process redesign and improved supply chain

\footnotetext{
${ }^{5}$ For discussion of the customer-driven interindustry IT effects, see Cheng and Nault (2005).
}

operations. To the extent that these variables correlate with supplier IT investment, our analysis would bundle these effects; still, some of the spillovers we find could be due to these other variables. However, as an enabling technology, supplier IT investment could be the catalyst for many of these other variables. It would be useful to differentiate between spillovers arising as unintended consequences of IT investment decisions upstream, and those that arise as a result of deliberate IT investments upstream that complement IT investments made downstream. With our industry-level data we are not able to separate unintended and deliberate spillovers. Firm-level data might not only provide the opportunity to separate the spillovers, but would be less subject to aggregation error, and depending on the market power of the firm, firm-level pricing may reflect the intangible benefits such as variety, quality and customer service. On the other hand, firm-level data is difficult to obtain, is often of questionable quality, and firms may be reluctant to disclose transactions with their trading partners. With the proliferation of electronic marketplaces, future research could exploit interfirm transaction data from trading partner networks such as Covisint to study the IT spillovers at the firm level.

Second, our data does not represent the whole economy. However, as seen in Table 2, our analysis of the 85 manufacturing industries captures a fairly large proportion of the interindustry transaction in the economy. Third, as with most other IT productivity studies, our IT investment measure does not include software. Our results should be interpreted as the spillovers of the IT investment in various categories of hardware. With increasing portions of IT investment on software, future research should measure spillovers from software investment. Lastly, we only consider IT spillovers from one step upstream, that is, we only consider IT spillovers from immediate suppliers. Downstream propagation of the benefits of upstream IT investments through the value chain is an exciting avenue for future research.

\section{Acknowledgments}

Helpful comments were provided by participants in seminars at Notre Dame University, the University of British Columbia, the CIBER conference at the University of Washington, Carnegie-Mellon University, the Hong Kong University of Science and Technology, the University of Florida, the University of Pennsylvania, New York University, the University of Calgary, and by the Management Science review team. The authors thank the Social Science and Humanities, and the Natural Science and Engineering Research Councils of Canada, the Department of Accounting and MIS in the Fisher College of Business at the Ohio State University, and the David B. Robson Endowment and the Informatics Research Center (iRC) in the Haskayne School of Business at the University of Calgary for support. 
The authors also thank Ibtihaj Bahaa for helpful research assistance.

\section{Appendix. Control for Industry Competitiveness}

In the main text, we argue that in competitive settings some of the benefit of investments in IT is passed on to the downstream customers, giving rise to supplier-driven IT spillovers. In order to see the impact of supplier industry competition on the IT spillovers, we use industry concentration as a control for competition in the estimation.

We obtained the concentration data for the four-digit SIC manufacturing industries in year 1992 from the U.S. Census Bureau website. The U.S. Census Bureau website has two measures of concentration: concentration ratios (including 4-firm, 8-firm, 20-firm, 50-firm concentration ratios) and the Herfindahl-Hirschman Index (HHI). Because we have to aggregate four-digit SIC industries into higher level threedigit SIC industries, we cannot use the concentration ratio. Instead we use the HHI. HHI is the sum of squares of the market shares of all firms in the industry. The data set also has a column of Value of Shipments (or Total Sales). So we use the HHI multiplied by the square of Value of Shipments to get the sum of square of the sales of all firms in the industry. We then aggregate this number and the Value of Shipments of four-digit SIC industries into three-digit SIC industries. The three-digit industry HHI is the aggregate sum of squared sales divided by the squared aggregate Value of Shipments.

We incorporate the HHI in our model by adding it in (5) as a control for the measurement error, because our argument is that the more competitive the supplier industry is, the more severe the measurement error of the intermediate input. Therefore, (5) becomes

$$
\epsilon_{j}=\mu \cdot z_{j}+\eta \cdot h h i_{j}
$$

where $h h i_{j}$ is the log of $j$ th industry's HHI. ${ }^{6}$ By plugging (8) into (4), we obtain our model with suppliers' $\mathrm{HHI}$ as the control:

$$
\begin{aligned}
y_{i}= & a+\alpha k_{i}+\beta l_{i}+\gamma z_{i}+\theta m_{i} \\
& +\varphi \sum_{j \neq i} \frac{V_{j i}}{\sum_{j \neq i} V_{j i}} z_{j}+\tau \sum_{j \neq i} \frac{V_{j i}}{\sum_{j \neq i} V_{j i}} h h i_{j},
\end{aligned}
$$

where $\tau=\theta \eta$.

Therefore, suppliers' HHI are averaged the same way as the suppliers' IT by using the input-output tables as the weight matrix. It turns out that this control for supplier industry competitiveness is insignificant ( $p$-value $=0.25$ for PSAR1 and 0.26 for $\mathrm{He}+$ PSAR1).

The reason for the insignificance of supplier industry competition might be due to the fact that the manufacturing industries are largely competitive. Less than $10 \%$ of the four-digit SIC manufacturing industries has HHIs greater than 1,800 , which is considered to be highly concentrated. After aggregation into three-digit SIC, only two out of the 98 three-digit SIC industries have an HHI greater than 1,800,

\footnotetext{
${ }^{6}$ We use log of $\mathrm{HHI}$ in order to be consistent with other terms in our model. We also tested our model using suppliers' HHI in index form and it was insignificant.
}

and 94 have an HHI lower than 1,000, which is considered to be relatively unconcentrated.

\section{References}

Baily, M. N., R. Z. Lawrence. 2001. Do we have a new e-conomy? Amer. Econom. Rev. 91(2) 308-312.

Bartelsman, E. J., R. J. Caballero, R. K. Lyons. 1994. Customerand supplier-driven externalities. Amer. Econom. Rev. 84(4) 1075-1084.

Brynjolfsson, E. 1994. Technology's true payoff. Informationweek (October 10) 34-36.

Brynjolfsson, E., L. M. Hitt. 1995. Information technology as a factor of production: The role of differences among firms. Econom. Innovation New Tech. 3(4) 183-200.

Brynjolfsson, E., L. M. Hitt. 1996. Paradox lost? Firm-level evidence on the returns to information systems spending. Management Sci. 42(4) 541-558.

Brynjolfsson, E., L. M. Hitt. 2000. Beyond computation: IT, organization transformation, and business performance. J. Econom. Perspective 14(4) 23-48.

Brynjolfsson, E., L. M. Hitt. 2003. Computing productivity: Firmlevel evidence. Rev. Econom. Statist. 85(4) 793-808.

Caballero, R., R. Lyons. 1992. External effects in U.S. procyclical productivity. J. Monetary Econom. 29 209-225.

Cachon, G. P., M. Fisher. 2000. Supply chain inventory management and the value of shared information. Management Sci. 46(8) 1032-1048

Çetinkaya, S., C. Lee. 2000. Stock replenishment and shipment scheduling for vendor-managed inventory systems. Management Sci. 46(2) 217-232.

Cheng, J., B. R. Nault. 2005. Customer-driven IT spillovers. Working paper, University of Calgary, Calgary, AB, Canada.

Chentrens, C., A. Andreassean. 2001. Layout and description for 192-order input-output tables: 1983-2000 historical and projected 2010. Prepared in the U.S. Bureau of Labor Statistics Office of Occupational Statistics and Employment Projections, November.

Cobb, C. W., P. H. Douglas. 1928. A theory of production. Amer. Econom. Rev. 18(Supplement) 139-165.

Conley, T. G., B. Dupor. 2003. A spatial analysis of sectoral complementarity. J. Political Econom. 111(2) 311-352.

Cooper, R., J. Haltiwanger. 1996. Evidence on macroeconomic complementarities. Rev. Econom. Statist. 78(1) 78-93.

Dewan, S., K. L. Kraemer. 2000. Information technology and productivity: Evidence from country-level data. Management Sci. 46(4) 548-562.

Dewan, S., C. Min. 1997. The substitution of information technology for other factors of production: A firm-level analysis. Management Sci. 43(12) 1660-1675.

Gordon, R. J. 2000. Does the "new economy" measure up to the great inventions of the past? J. Econom. Perspectives 14(4) 49-74.

Griliches, Z. 1971. Price Indexes and Quality Change: Studies in New Methods of Measurement. Harvard University Press, Cambridge, MA.

Griliches, Z. 1979. Issues in assessing the contribution of research and development to productivity growth. Bell J. Econom. 10(1) 92-116.

Griliches, Z., F. Lichtenberg. 1984. Interindustry technology flows and productivity growth: A reexamination. Rev. Econom. Statist. 66(2) 324-329.

Kokoski, M. 1993. Quality adjustment of price indexes. Monthly Labor Rev. (December) 34-46. 
Kokoski, M., K. Waehrer, P. Rozaklis. 2007. Using hedonic methods for quality adjustment in the CPI: The consumer audio products component. Working paper, U.S. Bureau of Labor Statistics, Washington, D.C.

Lee, B., A. Barua. 1999. An integrated assessment of productivity and efficiency impacts of information technology investments: Old data, new analysis, and evidence. J. Productivity Anal. 12 21-43.

Lee, H. L., K. So, C. Tang. 2000. The value of information sharing in a two-level supply chain. Management Sci. 46(5) 626-643.

Lichtenberg, F. R. 1995. The output contributions of computer equipment and personnel: A firm-level analysis. Econom. Innovation and New Tech. 3 201-217.

Liegey, P. R. 1994. Apparel price indexes: Effects of hedonic adjustment. Monthly Labor Rev. (May) 38-45.

Loveman, G. W. 1994. An assessment of the productivity impact of information technologies. T. J. Allen, M. S. Scott-Morton, eds. Information Technology and the Corporation of the 1990s: Research Studies. MIT Press, Cambridge, MA, 84-110.

Mahajan, J., A. J. Vakaria. 2004. Determining firm-level IT investments to facilitate value-chain activities: Should spillovers accruing to value-chain members be incorporated? Eur. J. Oper. Res. 156 665-682.

Melville, N., R. Ramirez. 2003. Assessing IT business value within interorganizational processes. Proc. Americas Conf. Inform. Systems, Tampa, FL. Association for Information Systems, Atlanta, GA

Mittal, N., B. R. Nault. 2006. Investments in information technology: Indirect effects and information technology intensity. Working paper, University of Calgary, Calgary, AB, Canada.
Mukhopadhyay, T., S. Kekre, S. Kalathur. 1995. Business value of information technology: A study of electronic data interchange. MIS Quart. 19(2) 137-156.

Oliner, S. D., D. E. Sichel. 2000. The resurgence of growth in the late 1990s: Is information technology the story? J. Econom. Perspective 14(4) 3-22.

Riggins, F. J., T. Mukhopadhyay. 1994. Interdependent benefits from interorganizational systems: Opportunities for business partner reengineering. J. Management Information Systems 11(2) 37-57.

Romano, A., G. Passiante, V. Elia. 2001. New sources of clustering in the digital economy. J. Small Bus. Enterprise Development 8(1) 19-27.

Scherer, F. M. 1982. Interindustry technology flows and productivity growth. Rev. Econom. Statist. 64(4) 627-634.

Sinclair, J., B. Catron. 1990. An experimental price index for the computer industry. Monthly Labor Rev. (October) 16-24.

Solow, R. M. 1957. Technical change and the aggregate production function. Rev. Econom. Statist. 39(August) 312-320.

STATA. 2005. Longitudinal/Panel Data Reference Manual. Stata Press, College Station, TX.

Stiroh, K. J. 2002. Information technology and the U.S. productivity revival: What do the industry data say? Amer. Econom. Rev. 92(5) 1559-1576.

Tallon, P. P., K. L. Kraemer, V. Gurbaxani. 2000. Executives' perceptions of the business value of information technology: A process-oriented approach. J. Management Inform. Systems 16(4) 145-173.

Wooldridge, J. M. 2002. Econometric Analysis of Cross Section and Panel Data. MIT Press, Cambridge, MA. 